\title{
Endosulfan Causes Neoplastic Changes in the Liver Cells of Mice
}

\author{
Arun Kumar1, Mohammad Ali1, Jitendra Kumar Singh1, Akhileshwari Nath1, \\ Sudhir Kumar Srivastava ${ }^{2}$, Ranjit Kumar ${ }^{1}$ \\ ${ }^{1}$ Research Centre, Mahavir Institute and Research Centre, Patna, India \\ ${ }^{2}$ Department of Zoology, Patna University, Patna, India \\ Email: arunk31@rediffmail.com
}

Received 2 May 2014; revised 2 June 2014; accepted 20 June 2014

Copyright (C) 2014 by authors and Scientific Research Publishing Inc. This work is licensed under the Creative Commons Attribution International License (CC BY). http://creativecommons.org/licenses/by/4.0/

\section{(c) (i) Open Access}

\section{Abstract}

The rapid growth in global population continues to challenge the world's ability to provide enough food. As one of the most crucial issues for human development, food production must increase to offset hunger and poverty as well as social unrest. To augment the yield of crops a variety of pesticides like Endosulfan, Rogor, Aldrin, Chlorpyrifos, etc. are being used liberally by the farmers. In the present investigation, Endosulfan was administered orally (daily) by gavage method to female Swiss albino mice group for 4 weeks @ $3.0 \mathrm{mg} / \mathrm{kg}$ b.w. After that, they were left for 6 months and then sacrificed and liver tissues were fixed for light microscopy and Transmission Electron Microscopic study. The histopathological study of Endosulfan administered group liver showed hepatocytes with congestion in central vein with less dense cytoplasm, haemorrhaged bile duct, degenerated cytoplasm and central vein with vacuolations in sinusoidal spaces. Neoplastic changes in hepatocytes are the major finding of study. The ultrastuctural study revealed dilation in the nuclear pore complex and massive movement of cytoplasmic material from cytoplasm to the nucleus which is major finding which denotes neoplastic changes. Presence of abundant free lying polyribosomes in the cytoplasm, which denotes neoplastic changes in the cellis also one of theimportant finding observed. The present study thus deciphers that Endosulfan toxicity leads to onset of neoplasia thence carcinogenesis in liver cells in Swiss albino mice which is the novel finding in the field of toxicology.

\section{Keywords}

Endosulfan, Neoplasia, Liver Cell, Light Microscopy, Transmission Electron Microscopy 


\section{Introduction}

Food problems have haunted mankind since time immemorial. With few technology breakthrough to increase yields, the food needs of growing population were historically met by expanding the cultivated area. It is also true that the green revolution has succeeded in transforming the Indian economy from a situation of severe food shortage into one where the country has not only become self-reliant in food production but has also been able to generate a sizable surplus for export. India is a predominantly agrarian country with about $60 \%-80 \%$ rural population. Pesticides are routinely used for advanced farming to improve crop yield and for control of different pests. The term pesticide covers a wide range of compounds including insecticides, fungicides, herbicides, rodenticides, molluscicides, nematocides, plant growth regulators and others. Among these, organochlorine (OC) insecticides, used successfully in controlling a number of diseases, such as malaria and typhus, were banned or restricted after the 1960's in most of the technologically advanced countries. Ideally a pesticide must be lethal to the pests, but not to non-target species, including man. Unfortunately, this is not so the controversy of use and abuse of pesticides has surfaced. The rampant use of these chemicals, under the adage, "if little is good, a lot more will be better" has played havoc with human and other life forms [1].

Among various organochlorines, Endosulfan is widely used in India. Endosulfan is classified in India as an "Extremely Hazardous” pesticide [2], "Moderately Hazardous chemical” by (WHO-class II), highly toxic substance [3] [4] and moderately hazardous pesticide after taking $\mathrm{LD}_{50}$ value [5]. Recently, Government of Kerala, India, banned this pesticide (Endosulfan) after its hazardous effect on the reproductive health of Kassaragod district cashew nut workers. Most of the cases related to male and female infertility and abnormal child birth were found. It was also confirmed by many authors [6]-[11].

Since, Endosulfan exposure had caused lots of health hazards among the cashew nut workers in Kerala, India it thence became a rationale to re-evaluate its carcinogenic effect in animal models. Endosulfan leads to liver carcinogenesis is the novel work ever added in this area. It is similar to the carcinogenic effects observed by many clinicians in cashew nut workers of Kassargod district of Kerala [12]. The present study thus, illustrates the carcinogenic activity of Endosulfan on the liver cells of Swiss albino mice.

\section{Materials \& Methods}

\subsection{Animals}

For the study female Swiss albino mice were procured from the animal house of Mahavir Cancer Institute \& Research Centre, Patna, Bihar, India (CPCSEA Regd. no. 1129/bc/07/CPCSEA, dated 13/02/2008) and their ethical approval for this study was obtained by the Institutional Animal Ethics Committee (IAEC). The age group of female mice for the experiments was 12 weeks old. The average body weight of experimental mice was $30 \pm 2 \mathrm{gm}$. All the female mice were acclimatized for one week prior to the experimentation. The animals had free access to water and feed pellets (prepared mixed formulated feed by the laboratory itself) [13].

\subsection{Test Pesticide}

The commonly used pesticide-Endosulfan (Excel India Pvt. Ltd. Mumbai with EC 35\%) was obtained from the local pesticide market of Patna.

\subsection{Experimental Design}

The animals were grouped into two groups, Group I, control $n=6$, received distilled water as drinking water while Group II, Endosulfan treated group $(\mathrm{n}=24)$ received endosulfan $3 \mathrm{mg} / \mathrm{kg}$ b.w daily by gavage method for 4 weeks after estimation of $\mathrm{LD}_{50}$ value which was found to be $7 \mathrm{mg} / \mathrm{kg}$ body weight. Then, the animals were left without treatment for 6 months to observe any adverse effect. After 6 months, the animals were sacrificed and their liver tissues were fixed in respective fixatives.

\subsection{Histopathology \& Transmission Electron Microscopy}

All mice were sacrificed after the scheduled period. A midsaggital incision was made and liver tissue from all the mice were removed and fixed in $10 \%$ neutral formalin for light microscopy study. For Transmission Electron 
microscopy it was fixed in $2.5 \%$ gluteraldehyde in $0.1 \mathrm{M}$ sodium phosphate buffer $(\mathrm{pH} 7.2)$ with in $24 \mathrm{~h}$ of removal. After rinsing with phosphate buffer, tissues were postfixed with $2 \%$ osmium tetraoxide in sodium phosphate buffer. Dehydration was accomplished by gradual ethanol series and tissues were embedded in epoxy resin. Semithin sections were stained with toluidine blue and examined with a light microscope (Olympus, LXi, Tokyo, Japan). Ultrathin sections (800 nm) were stained with uranyl acetate and lead citrate. Sections were then viewed and photographed with Morgagini - 268 D TEM (SEI Co.) at SAIF-EM facility Unit (Sophisticated Analytical Instruments Facility) at All India Institute of Medical Sciences (AIIMS), New Delhi, India. For the light microscopic study, the Haemotoxylin-Eosin stained slides were prepared and the sections were viewed under light microscope.

\section{Results}

\subsection{Morbidity and Mortality}

The mice after Endosulfan exposure ( $3 \mathrm{mg} / \mathrm{Kg}$ b.w./day) for 4 weeks have shown signs of toxicity such as nausea, nose bleeding, lack of body co-ordination, general body weakness and loss of body weight. But, in the mice which were left for 6 months, there was further significant decrease in the bodyweight denotes the degree of toxicity.

\subsection{Histpathological Findings}

Hepatocytes, sinusoids and sinusoidal cells structures in Group I (control group) were normal as normal architecture of hepatocytes well arranged near central vein were observed (Figure 1). In Group II (Endosulfan treated group) hepatocytes with haemorrhaged central vein and bile duct were observed. Vacuolations in sinusoidal spaces with numerous Kupffer's cells were also observed. The most important finding is the neoplastic growth as observed in the section (Figure 2) denotes the malignancy in the hepatocytes.

\subsection{Transmission Electron Microscopic Findings}

In the transmission electron microscopic examination, degeneration in hepatocytes in Endosulfan treated group was evident as pseudopodia like formation of nuclear membranes of two nuclei were observed, denotes high degree of degeneration (Figure 3) in comparison to the control hepatocyte section (Figure 4). Rupture in the nuclear membranes with dilations in the nuclear pore complex and their movement into the cytoplasmic region is clearly observed (Figure 5) with formation of neoplastic bodies (Figure 6). The highly significant result showed the migration of cytoplasmic material into the nucleus (Figure 7) i.e. nuclear inclusion denotes the neoplastic condition as the nuclear inclusion shows mitochondria with rough endoplasmic reticulum (Figure 8). Free lying polyribosomes in cytoplasm also denote the neoplastic condition in the hepatocytes.

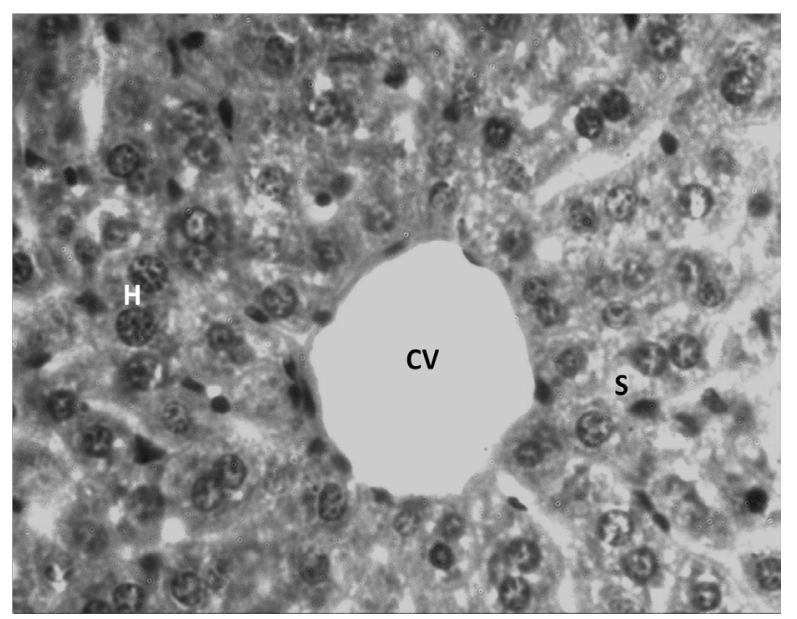

Figure 1. Light microphotograph (Haemotoxylin-Eosin (H\&E) stained) section of control liver showing normal architecture of central vein $(\mathrm{CV})$ with hepatocytes $(\mathrm{H})$ well arranged in sinusoids $(\mathrm{S}) . \times 800$. 


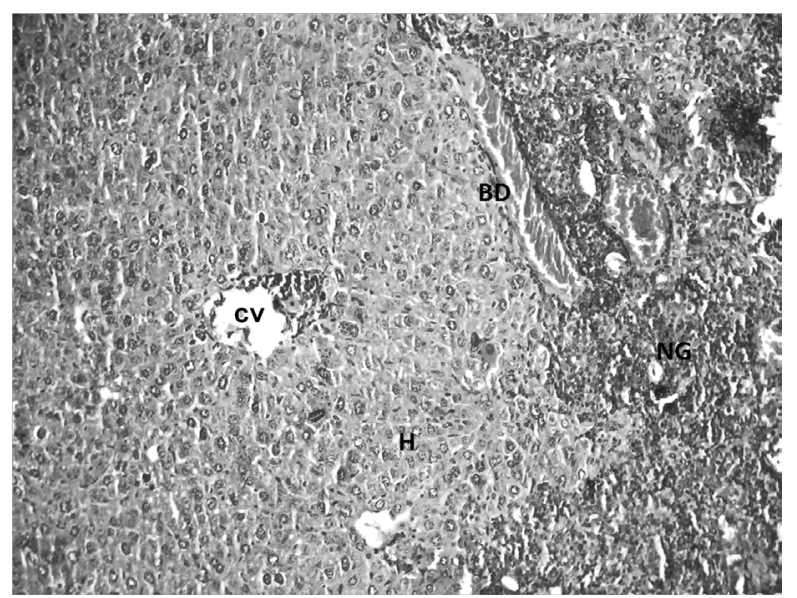

Figure 2. Light microphotograph (Haemotoxylin-Eosin (H\&E) stained) section of Endosulfan treated liver showing degeneration in the hepatocytes $(\mathrm{H})$ with haemorrhage in central vein $(\mathrm{CV})$ and bile duct (BD). Vacuolations in sinusoidal spaces with numerous Kupffer's cells and neoplastic growth (NG) in the section are also clearly visible. $\times 500$.

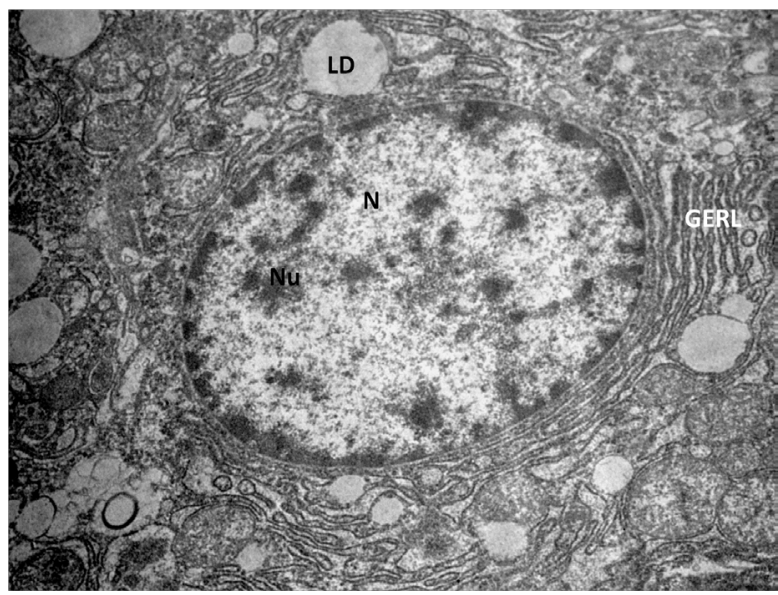

Figure 3. Transmission Electron micrograph section of control liver showing normal architecture of nucleus $(\mathrm{N})$ with nucleolus (Nu), the Golgi pathway (GERL) and lipid droplets (LD). $\times 14,000$.

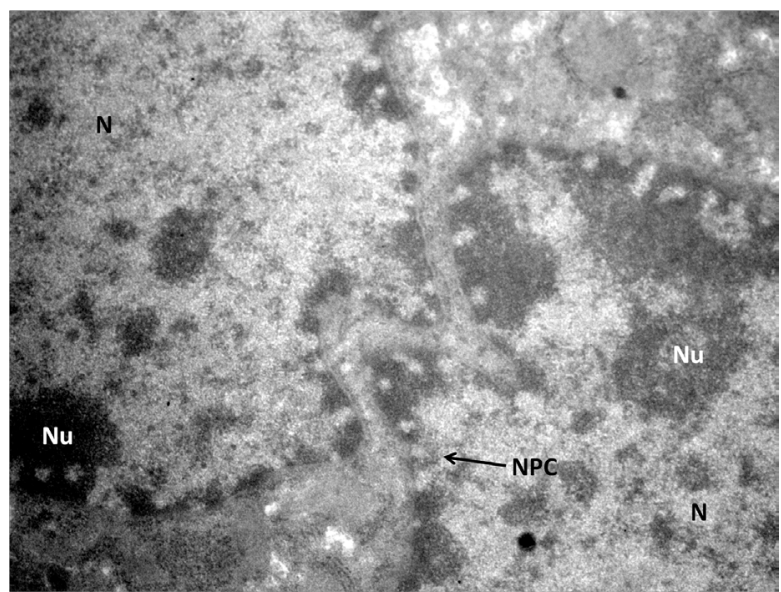

Figure 4. Transmission Electron micrograph section of Endosulfan treated liver showing hepatocytes with pseudopodia like formation of nuclear membrane of the two nuclei $(\mathrm{N})$. The dilated nuclear pore complex (NPC) denotes high degree of degeneration. $\times 56,000$. 


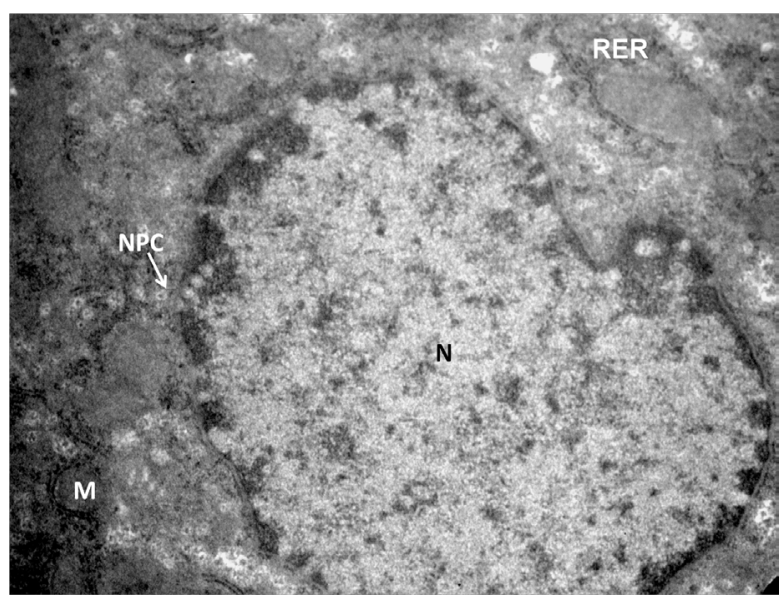

Figure 5. Transmission Electron micrograph section of Endosulfan treated liver showing hepatocyte with degeneration in rough endoplasmic reticulum (RER) and mitochondria (M). Ruptures in nuclear membrane, while migration of nuclear pore complexes (NPC) in to the cytoplasmic region, denotes high degree of degeneration. $\times 28,000$.

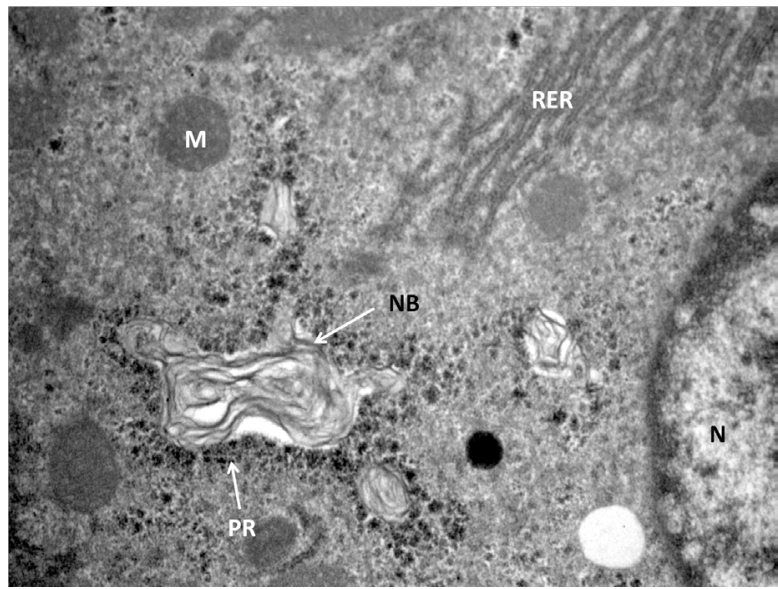

Figure 6. Transmission Electron micrograph section of Endosulfan treated liver showing hepatocyte in degenerative condition with neoplastic body (NB) 28,000.

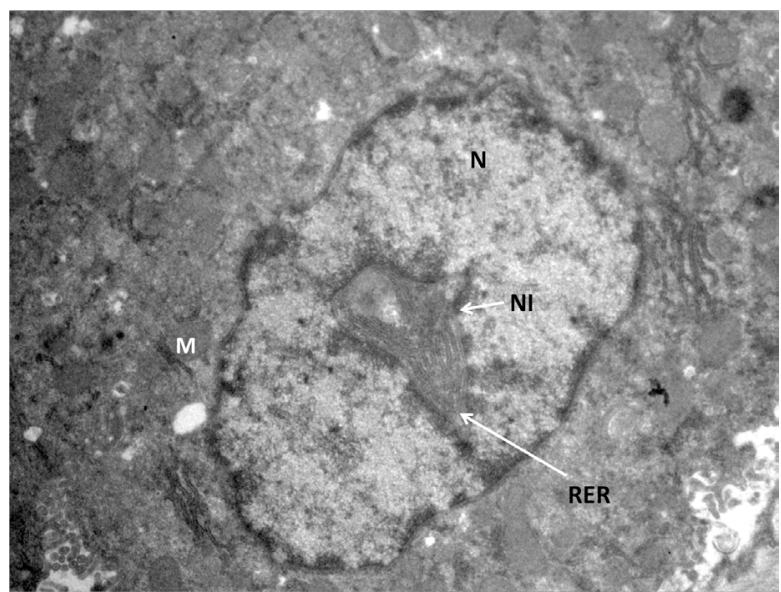

Figure 7. Transmission Electron micrograph section of Endosulfan treated liver showing peculiar condition of nuclear inclusion (NI) containing RER and mitochondria (M). Rupture in the nuclear membrane and degenerated cytoplasm is observed. $\times 14,000$. 


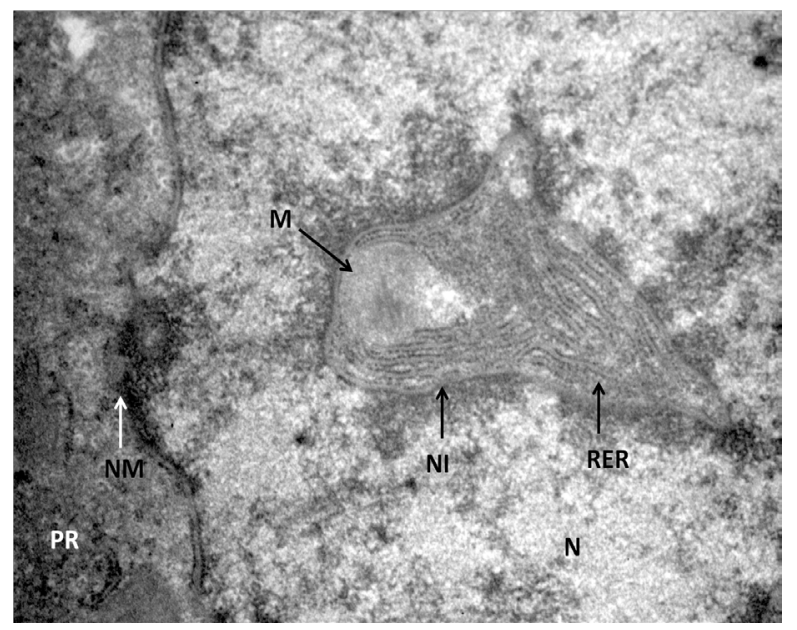

Figure 8. Transmission Electron micrograph section of Endosulfan treated liver showing magnified view of Figure 7, showing nuclear inclusion (NI). The nuclear inclusion contains mitochondria (M), RER with ruptured nuclear membrane (NM), free lying polyribosomes (PR) in the cytoplasm. $\times 56,000$.

\section{Discussion}

Endosulfan is an organochlorine pesticide causing major damage to the liver injury. Peroxidation of membrane lipids and formation of free radicals are the major cause responsible for the toxic effects of Endosulfan. Under normal conditions, the free radical levels in body are low and the healthy organisms can ameliorate or neutralize their effects by free radical scavangers such as antioxidants. Lipid peroxidation, particularly those containing polyunsaturated fatty acids can significantly change the properties of biological membranes. In the present study, Endosulfan has caused high degree of degeneration at cellular as well as sub cellular levels. The haemorrhages in central vein, bile duct and neoplastic growths in hepatocytes denotes neoplastic condition while degeneration in rough endoplasmic reticulum (RER) leads to cleavage of ribosomes from the RER making in free lying polyribosomes in the cytoplasm. The membranes have lost their integrity leading to cyto-nucleic pressure causing migration of cytoplasmic materials into the nucleus i.e. nuclear inclusion. This is the indicator of neoplasia as this type of pattern is generally observed in neoplastic cells [14].

In the other studies on Endosulfan, it was observed that it causes degeneration in hepatic cells of rats [15]-[19]. Impact of endosulfan on fish at histopathological and biochemical and haematological levels have also been well studied [20]-[25]. In the present histopathological study also, it was observed with many structural damages, neoplastic growth in the hepatocytes, degeneration in cytoplasmic organelles and nuclei of the hepatocytes. Molecular mechanisms underlying the carcinogenic effects of endosulfan in human liver showed phenotypical effects of endosulfan on HepG2 liver cells. Endosulfan disrupted the anoikis process and cells exposed to endosulfan were initially sensitized to anoikis and thereafter recovered their resistance to this process. Altogether, the results indicate that endosulfan profoundly alters the phenotype of liver cells by inducing cell detachment and partial EMT as well as disrupting the anoikis process. All these events account, at least in part, for the carcinogenic potential of endosulfan in liver [26]. In a parallel study, it has been reported that endosulfan exposure causes ovarian malignancy in Swiss albino mice [27]. Endosulfan had not only led to cause liver cancer among cashew nut workers but also of throat, blood and uterus [12]. Endosulfan is probably responsible of causing gall bladder cancer in humans in Gangetic belt of eastern and western India has been well documented [28]. Thus, from the entire study, it is revealed that endosulfan exposure to experimental animals causes hepatic injury at great extent leading to neoplastic changes in the hepatic cells.

\section{Acknowledgements}

The authors are thankful to SAIF-EM facility Unit (Sophisticated Analytical Instruments Facility) at All India Institute of Medical Sciences (AIIMS), New Delhi, India and Mahavir Cancer Institute \& Research Centre, Patna, Bihar, India for providing infrastructural facilities. 


\section{Conflict of Interest}

The authors report no conflicts of interest. The authors alone are responsible for the content and writing of the paper.

\section{References}

[1] ICMR Bulletin (2001) Pesticide Pollution: Trends and Perspective Indian Council of Medical Research, Government of India, New Delhi, 9, 1-12.

[2] ITRC Industrial Toxicology Research Centre (CSIR) (1989) Toxicity Handbook Vol. III, Pesticides-A, (TDS-161) 292-297.

[3] EXTOXNET (1998) Extension Toxicology Network. Internet Site. A Pesticide Information of Cooperative Extension Officer of Cornell University, Michigan State University, Oregon State University \& University of California at Davis.

[4] ATSDR (1993) Toxicological Profile for Endosulfan, United States Agency for Toxic Substances and Disease Registry, Atlanta, GA, Available from NT’s Springfield, V.A. PB-93-182558.

[5] Quijano, R.F. (2000) Risk Assessment in a Third World Reality: An Endosulfan Case History. International Journal of Occupational and Environmental Health, 6, 312-317. http://dx.doi.org/10.1179/oeh.2000.6.4.312

[6] Sinha, D.K., Verma, P., Kumar, A. and Nath, A. (2004) Changes in Hepatic Cells of Mice Musmusculus under Sublethal Dose of Endosulfan. Journal of Ecophysiology and Occupational Health, 4, 179-183.

[7] Sinha, P., Verma, P., Kumar, A. and Nath, A. (2004) Testicular Atrophy in Mice Musmusculus under Sublethal Doses of Endosulfan. Journal of Ecophysiology and Occupational Health, 4, 191-196.

[8] Engel, L.S., O’ Meara, E.S. and Schwartz, S.M. (2000) Maternal Occupation in Agriculture and Risk of Limb Defects in Washington State, 1980-1993. Scandinavian Journal of Work, Environment Health, 26, 193-198. http://dx.doi.org/10.5271/sjweh.531

[9] Rojas, A., Ijeda, M.E. and Barrza, X. (2000) Congenital Malformation and Pesticide Exposure. Revista Médica de Chile, 128, 399-404. http://dx.doi.org/10.4067/S0034-98872000000400006

[10] Weidner, I.S., Moller, H., Jenser, T.K. and Skakkebaek, N.E. (1998) Cryptorchidism and Hypospadias in Sons of Gardeners and Farmers. Environmental Health Perspectives, 106, 793-796.

[11] Nurminen, T. (1995) Maternal Pesticide Exposure and Pregnancy Outcome. Journal of Occupational and Environmental Medicine, 37, 935-940. http://dx.doi.org/10.1097/00043764-199508000-00008

[12] THANAL (2002) Thanal Conservation Action \& Information Network. Long Term Monitoring-The Impact of Pesticides on the People and Ecosystem (LMIPPE) Part II Report Preliminary Findings of the Survey on the Impact of Aerialspraying of Endosulfan on the People and Ecosystem in Kasaragod, Kerala, India, 1-22.

[13] Dhar, D.C. (1959) Preparation of a Balanced Stock Diet for Laboratory Animals (Rats \& mice). Journal of Scientific Industrial Research, 18C, 250-253.

[14] Ghadially, F.N. (1980) Diagnostic Electron Microscopy of Tumors. Butterworths, London, 32-34.

[15] Rouimi, P., Zucchini-Pascal, N., Dupont, G., Razpotnik, A., Fouché, E., De Sousa, G. and Rahmani, R. (2012) Impacts of Low Doses of Pesticide Mixtures on Liver Cell Defence Systems. Toxicology in Vitro, 26, 718-726. http://dx.doi.org/10.1016/j.tiv.2012.03.015

[16] Silva, M.H. and Gammon, D. (2009) An Assessment of the Developmental, Reproductive, and Neurotoxicity of Endosulfan. Birth Defects Research Part B: Developmental and Reproductive Toxicology, 86, 1-28. http://dx.doi.org/10.1002/bdrb.20183

[17] Bharathi, S.P., Raj, H.M., Jain, S., Banerjee, B.D., Ahmed, T. and Arora, V.K. (2013) Role of Pesticides in the Induction of Tumor Angiogenesis. Anticancer Research, 33, 231-240.

[18] Wade, M.G., Desaulniers, D., Leingartner, K. and Foster, W.G. (1997) Interactions between Endosulfan and Dieldrin on Estrogen-Mediated Processes in Vitro and in Vivo. Reproductive Toxicology, 11, 791-798. http://dx.doi.org/10.1016/S0890-6238(97)00062-2

[19] Siddiqui, M.K., Anjum, F. and Qadri, S.S. (1987) Some Metabolic Changes Induced by Endosulfan in Hepatic and Extra Hepatic Tissues of Rat. Journal of Environmental Science and Health, Part B: Pesticides, Food Contaminants, and Agricultural Wastes, 22, 553-564. http://dx.doi.org/10.1080/03601238709372572

[20] Kumar, N., Jadhao, S.B., Chandan, N.K., Kumar, K., Jha, A.K., Bhushan, S., Kumar, S. and Rana, R.S. (2012) Dietary Choline, Betaine and Lecithin Mitigates Endosulfan-Induced Stress in Labeo rohita Fingerlings. Fish Physiology and Biochemistry, 38, 989-1000. http://dx.doi.org/10.1007/s10695-011-9584-y

[21] Kumar, N., Jadhao, S.B., Chandan, N.K., Aklakur, M. and Rana, R.S. (2013) Methyl Donors Potentiates Growth, Me- 
tabolic Status and Neurotransmitter Enzyme in Labeo rohita Fingerlings Exposed to Endosulfan and Temperature. Fish Physiology and Biochemistry, 38, 1343-1353. http://dx.doi.org/10.1007/s10695-012-9622-4

[22] Salvo, L.M., Bainy, A.C., Ventura, E.C., Marques, M.R., Silva, J.R., Klemz, C. and de Assis, H.C.S. (2012) Assessment of the Sublethal Toxicity of Organochlorine Pesticide Endosulfan in Juvenile Common Carp (Cyprinus carpio). Journal of Environmental Science and Health Part A: Toxic/Hazardous Substances \& Environmental Engineering, 47, 1652-1658.

[23] Sarma, K., Pal, A.K., Sahu, N.P., Dalvi, R.S., Chatterjee, N., Mukherjee, S.C. and Baruah, K. (2012) Acute and Chronic Effects of Endosulfan on the Haemato-Immunological and Histopathological Responses of a Threatened Freshwater Fish, Spotted Murrel, Channa punctatus. Fish Physiology and Biochemistry, 38, 499-509. http://dx.doi.org/10.1007/s10695-011-9530-z

[24] Zhang, M., Wu, Y.H., Zhou, X.Q. and Zhou, H.N. (2012) The Effects of Endosulfan on the Growth and Erythrocyte Immune Function of Mongolian Gerbils (Meriones unguiculatus). Immunopharmacology and Immunotoxicology, 34, 754-762. http://dx.doi.org/10.3109/08923973.2011.653647

[25] Pandey, S., Ahmad, I., Parvez, S., Bin-Hafeez, B., Haque, R. and Raisuddin, S. (2001) Effect of Endosulfan on Antioxidants of Freshwater Fish Channa punctatus Bloch: 1. Protection against Lipid Peroxidation in Liver by Copper Preexposure. Archives of Environmental Contamination and Toxicology, 41, 345-352. http://dx.doi.org/10.1007/s002440010258

[26] Peyre, L., Zucchini-Pascal, N., de Sousa, G. and Rahmani, R. (2012) Effects of Endosulfan on Hepatoma Cell Adhesion: Epithelial-Mesenchymal Transition and Anoikis Resistance. Toxicology, 300, 19-30.

[27] Singh, J.K., Nath, A., Ali, M., Kumar, A. and Kumar, R. (2010) Endosulfan Exposure Causes Ovarian Malignancy in Swiss Albino Mice. Global Journal of Environmental Science and Technology, 1, 01-04.

[28] Shukla, V.K., Rastogi, A.N., Adukia, T.K., Raizada, R.B., Reddy, D.C. and Singh, S. (2001) Organochlorine Pesticides in Carcinoma of the Gallbladder: A Case-Control Study. European Journal of Cancer Prevention, 10, 153-156. http://dx.doi.org/10.1097/00008469-200104000-00006 
Scientific Research Publishing (SCIRP) is one of the largest Open Access journal publishers. It is currently publishing more than 200 open access, online, peer-reviewed journals covering a wide range of academic disciplines. SCIRP serves the worldwide academic communities and contributes to the progress and application of science with its publication.

Other selected journals from SCIRP are listed as below. Submit your manuscript to us via either submit@scirp.org or Online Submission Portal.
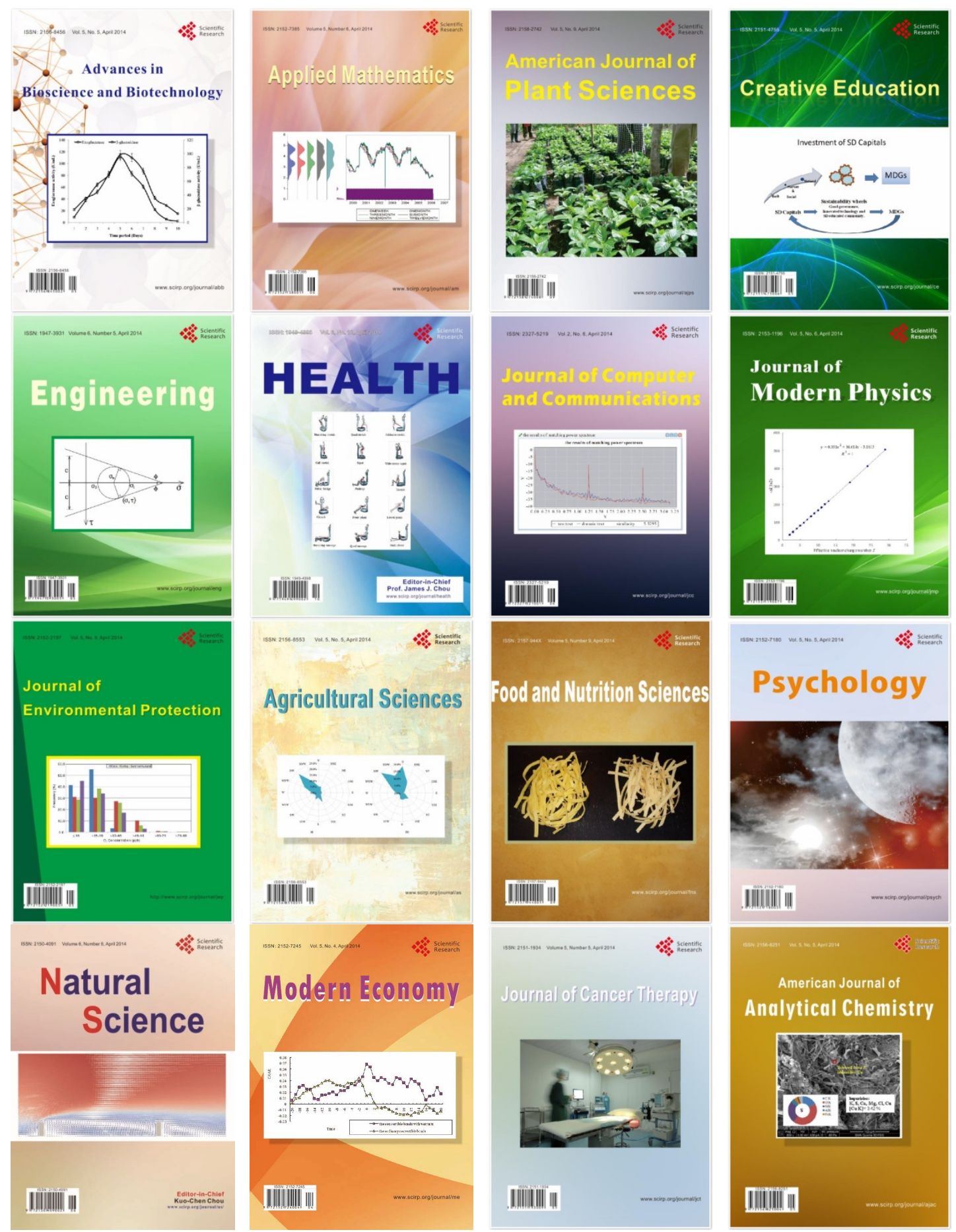